\title{
PROGRESO Y CULTURA: ICONOLOGÍA DEL PAPEL MONEDA DE COSTA RICA EN EL PERÍODO LIBERAL
}

\author{
PROGRESS AND CULTURE: ICONOLOGY OF \\ PAPER MONEY OF COSTA RICA'S LIBERAL PERIOD
}

\author{
LEONARDO SANTAMARÍA MONTERO \\ Universidad de Costa Rica
}

Resumen: Análisis iconográfico e iconológico sobre un ejemplar de papel moneda costarricense perteneciente a la primera década del siglo XX. Investigación realizada mediante el uso de fuentes primarias y secundarias, siguiendo el método iconográfico y respetando el orden gradual de su aplicación. Logrando así rastrear el origen iconográfico del dios griego Hermes, su vínculo artístico-simbólico con la élite centroamericana de la época, la temática representada en dicho billete y el estilo académico-estadounidense del diseño utilizado. Por otro lado, se trazan estrechas relaciones entre el pensamiento político liberal costarricense y la filosofía francesa conocida como Positivismo social; tomando así como figura principal al pensador Auguste Comte, teórico más influyente entre la élite latinoamericana de la segunda mitad del siglo XIX y la primera del siglo XX. Se identifica al pensamiento positivo como el origen del proyecto liberal costarricense, el cual pretendía moralizar y civilizar a la población mediante la transformación cultural, aspirando a homologarse con la cultura — según ellos - más desarrollada: la europea. Tomando como máxima social las nociones de Orden y Progreso, el proyecto liberal se sirvió de distintos medios para aplicar su programa de ascenso social internacional, y entre estas vías utilizó al papel moneda como soporte visual y conceptual, en donde la élite costarricense imprimió la cultura de su época, sus sueños, ideologías y paradigmas. De este modo, se evidencia el proceso de imposición cultural comandado por los mismos lideres costarricenses, quienes despreciaban la cultura nacional y mantenían sus metas en Europa. Por ello el estudio de este momento histórico se constituye como vital para entender este primer proyecto oficial para la construcción de una identidad nacional costarricense, mismo que se sirvió de las artes y de las imágenes en general para intentar cumplir su objetivo.

Palabras clave: Iconología, Costa Rica, siglo XIX, Numismática, Historia cultural, Positivismo Social.

Abstract: Iconographic and iconological analysis of an early XX century costa rican piece of paper money. Research conducted using primary and secondary sources, following the iconographic method and by respecting the gradual implementation. Achieving the iconographic origin 
of the greek god Hermes, his artistic and symbolic link with the costa rican elite of the time, the theme of the engraving and the engraver's artistic style. On the other hand, close relations between costa rican liberal political thought and the French social philosophy known as positivism are plotted; taking and headline thinker Auguste Comte, more influential among Latin American elites in the second half of the nineteenth century and early twentieth century theorist. Positive thinking is identified as the source of the Costa Rica liberal project, which sought to moralize and civilize the population through cultural transformation, aspiring to be approved with the culture, they argued more developed: the European. On the high social notions of Order and Progress, the liberal project drew various means to implement its program of international social ascent, and between these pathways used paper money as visual and conceptual support, wherein the printed costa rican elite culture of their time, their dreams, ideologies and paradigms. Thus, the process of costa rican cultural imposition led by leaders who despised national culture and kept their goals in Europe. Thus the study of this historical moment is as vital to understand the first official project for the construction of a costa rican national identity.

Keywords: Iconology, Costa Rica, 19th century, Numismatics, Cultural History, Sociological Positivism.

\section{NUMISMÁTICA E ICONOLOGÍA: DE IMÁGENES, TEXTOS E} IDEAS.

El estudio de la cultura siempre se ha abordado desde diversas perspectivas de las ciencias sociales y disciplinas humanísticas. Para ello se analiza, entre otros documentos, literatura, actas, discursos o imágenes. En el caso de este estudio, utilizaremos textos e imágenes (fuentes primarias y secundarias). Así, nuestro ensayo se limitará al análisis de una imagen en específico. Partiendo de ella, se trazará una línea histórica a través de la revisión de imágenes, textos e ideas anteriores y contemporáneas de nuestro caso de estudio. Como objetivo buscaremos acceder a una aproximación del significado que tuvo esta imagen para la cultura de su época, o al menos a un esbozo del programa intelectual que produjo tal imagen.

Evidentemente para lograr esto, habrá que utilizar una metodología de investigación y análisis. Para ello, recurriremos a una rama de la Historia del Arte, un método que fue estructurado por Erwin Panofsky (1892-1968) a inicios del siglo XX y que se consolidó como uno de los más efectivos para el análisis de imágenes: el método iconográfico e iconológico. Específicamente, utilizamos la 
metodología presentada en el primer capítulo ${ }^{1}$ del texto El significado en las Artes Visuales $^{2}$ (1955), propuesta de análisis dividida en tres grados ${ }^{3}$ : descripción preiconográfica ${ }^{4}$, análisis iconográfico ${ }^{5}$ y síntesis iconológica ${ }^{6}$.

Aunada a la iconografía e iconología, la numismática se constituye para nuestra investigación como una herramienta vital para un análisis efectivo del ejemplar de papel moneda a estudiar. De este modo, numismática e iconología son empleadas en conjunto en los tres grados de nuestra investigación. Relativo a la numismática, hemos revisado bibliografía costarricense publicada por el Museo de Numismática y por investigadores independientes especialistas en el estudio de las monedas y billetes nacionales. Además, se han revisado catálogos mundiales de papel moneda, específicamente los tomos correspondientes a la época a estudiar, mismos que funcionarán para la Historia del estilo e Historia de los tipos.

\section{PROGRESO Y CULTURA: ICONOLOGÍA DEL PAPEL MONE- DA DE LA COSTA RICA LIBERAL.}

Francia Republicana... gran metrópoli del mundo culto, de esa maestra insigne del género humano — nación a la cual nosotros los costarricenses profesamos hondo y filial cariño y somos los primeros en rendir pleito homenaje en orden a ciencia, arte y literatura. Inglaterra - señora absoluta de los mares- reservada, adusta, sagaz, calculadora hasta el exclusivismo; Francia - arbitra suprema del mundo intelectual - amable, culta, espiritual, emprendedora, generosa hasta la prodigalidad. Londres se nos antoja un gigantesco bazar; en Paris vemos una ex-

\footnotetext{
1 "1. Iconografía en Iconología: introducción al estudio del arte del Renacimiento".

${ }^{2}$ E. PANOFSKY, El significado en las artes visuales, Madrid, 1955, pp. 45-77.

${ }^{3}$ Para una explicación más rigurosa del método consultar: E. PANOFSKY, On the Relationship of Art History and Art Theory: Towards the Possibility of a Fundamental System of Concepts for a Science of Art, trad. Jas' Elsner; Katharina Lorenz, Chicago, 2008.

${ }^{4}$ Esta es la primera parte del método, donde se debe de describir lo que observamos sin caer en un formalismo total, sino que se deben de identificar los objetos representados. Esta fase deberá de verse revisada por una Historia del estilo.

${ }^{5}$ Esta es la segunda fase del método, donde se debe de identificar los temas representados, ya sean historias, alegorías o mitos. Esta fase debe de ser revisada por una Historia de los tipos, donde el investigador debe de consultar, además de imágenes, fuentes literarias relativas al tema identificado.

${ }^{6}$ Esta es la tercera y última fase del método, donde se contraponen las dos fases anteriores, además del contexto de la época, buscando la mayor aproximación hacia el significado original de la obra. Esta fase debe de ser revisada por una Historia de las ideas.
} 
celsa cátedra abierta a todos los pueblos de la tierra. ¡Admiramos a Cartago; pero nuestro ideal es Atenas! ${ }^{7}$

La década de 1890 es particularmente importante para todo estudioso de la Historia de la Cultura costarricense, pues fue en las administraciones RodríguezZeledón e Ylgesias-Castro que el Estado públicamente manifestó su preocupación por invertir en la construcción de la cultura nacional ${ }^{8}$. Interés en civilizar a la población que no se limitó a un debate político e intelectual entre la élite costarricense, sino que se plasmó en una serie de proyectos que cargaron la agenda gubernamental hasta la década de 1930, cuando la recesión económica norteamericana y cambios políticos nacionales marcaron en Centroamérica la decadencia de los llamados estados liberales.

Como antes se mencionó, esta investigación se centrará el análisis de un ejemplar de papel moneda. Podría parecer inusual el hecho de realizar un abordaje iconográfico e iconológico — comúnmente utilizado en obras de arte ${ }^{9}$ — sobre un objeto tan banal y masivo como lo es un billete. Sin embargo, para esta investigación, entenderemos al papel moneda como un soporte no solo visual, sino también conceptual, en el cual se imprime tinta, pero además la ideología de un momento histórico y de un círculo social defensor de tal ideología.

Sin duda alguna todo diseño de papel moneda es un ejemplar único e igual de valioso culturalmente respecto a los demás; mas podríamos hablar de casos especialmente particulares, como lo es el reverso del billete de 1 colón emitido por el Banco Anglo Costarricense entre los años de 1903 a 1917 (Fig. 1). Decimos esto, porque la imagen que se nos presenta inmediatamente nos remite a una cultura totalmente ajena a la América de albores del siglo XX. Pero por ahora no mencionaremos el contexto de este billete y nos enfocaremos en la imagen como tal: ¿Qué estamos viendo?

Bajo una primera lectura, este ejemplar de papel moneda podría parecernos uno más de tantos, esto por la paleta de colores utilizada: verde, gris y negro, pre-

\footnotetext{
7 “Boletín de las Escuelas Primarias, San José, 24 de agosto de 1896, No. 40, tomo II", en F. QUESADA AVENDAÑO, La modernización entre cafetales. San José, Costa Rica, 1880-1930, Helsinki, 2007, p. 81.

${ }^{8}$ Más adelante ahondaremos en el contexto político e ideológico de nuestra época de estudio.

${ }^{9}$ Definir arte ha sido una de las mayores problemáticas teóricas a lo largo de la historia de múltiples ramas del conocimiento. Mas podríamos buscar una definición lo más aproximada posible, afirmando así, que el arte es producto de una actividad estrictamente humana, la cual busca un fin estético y se constituye como una manifestación cultural de un pueblo o grupo social. Bajo esta visión, muchos de los objetos que tal vez en el momento de su producción no fuesen concebidos como arte pasarán a convertirse en motivo de estudio de la Historia del Arte, debido a que representan la cultura de una época, sus sueños, ideologías y paradigmas.
} 
sentados en diversas tonalidades sobre un fondo blanco. Además las dimensiones de este billete corresponden a un rectángulo, muy similar al formato utilizado actualmente ${ }^{10}$. Sobre las imágenes representadas, en el caso del anverso ${ }^{11}$ (Fig. 3) vemos en el centro y dentro de un ovalo, el rostro de un hombre; sobre este, una tipografía donde podemos leer "EL BANCO ANGLO COSTARRICENSE", letras ubicadas en el centro de dos cifras numéricas impresas en rojo en idénticas “047712”; junto al hombre del retrato, vemos dos números “1”, diseñados con un afán decorativo y rodeados de complejas tramas encerradas en una figura similar a una flor. Es este mismo diseño del "1" dentro de esta especie de flor lineal, el que podemos encontrar en las cuatro esquinas del billete, pero en este caso fueron colocadas con orientación diagonal en la sección superior. Además, el diseño de este ejemplar está cargado de numerosos patrones decorativos constituidos por tramas tanto en tonos grises como en matices coloridos.

Ahora, girando el billete y observando su reverso, podemos ver un diseño menos saturado y con una composición más armoniosa. Destacando en el centro la figura de un hombre desnudo a excepción de un par de sandalias y un sombrero con lo que parecieran ser alas, además de sostener una especie de bastón entre sus manos. Este hombre se presenta sentado en una máquina y mirando hacia la esquina superior derecha del rectángulo. Bajo él se coloca la misma leyenda con las palabras "BANCO ANGLO COSTARRICENSE", también se repite el mismo diseño del número " 1 " dentro de un patrón decorativo lineal. Al igual que en el anverso, el reverso cuenta con diversos diseños decorativos; mas en el caso del segundo vemos como la composición deja más espacios libres respecto al primero. Finalmente podemos observar hacia el centro en el inferior del rectángulo las palabras "AMERICAN BANK NOTE COMPANY".

A nivel de diseño, vemos como la imagen es producto de la impresión de un grabado probablemente en metal, el cual —obedeciendo a la naturaleza de esta técnica artística - se compone de líneas que dibujan las formas mediante el uso de tramas para lograr el efecto de volumen y perspectiva. Además es evidente como la figura de este hombre desnudo responde a un estilo naturalista, en el cual

${ }^{10}$ Sobre las dimensiones del papel moneda, es importante recordar que los primeros vales emitidos en Costa Rica durante el siglo XIX fueron diseñados con un formato cuadrado o rectangular con mayor longitud en el ancho respecto al alto (Fig. 2); de este modo, el billete que acá analizamos corresponde a una evolución de estos primeros billetes, siendo parte de la tendencia a nivel de formato que se mantuviera desde la segunda mitad del siglo XIX, todo el siglo XX e inicios de siglo XXI.

${ }^{11}$ El anverso del billete solo será mencionado en la fase pre-iconográfica, debido que el presente análisis se concentrará en el diseño del reverso. 
se busca representar las cosas lo más apegadas a lo percibido por el ojo humano; pero esto no es todo, sino que el estilo utilizado también nos remite a cierta idealización de la figura humana, respondiendo a cánones de proporciones académicos. Estos rasgos - y tomando en cuenta el período histórico en que nos hemos ubicado - nos revela que el grabado original posiblemente fuese realizado por un artista formado bajo los cánones de la Academia francesa o bien la inglesa ${ }^{12}$.

Si bien es cierto, a la hora de revisar los antecedentes artísticos de la época, nos encontraremos con el impresionismo y las numerosas vanguardias de finales del siglo XIX e inicios del XX. Sin embargo, nuestro caso pertenece aun a la tradición artística de la época, misma que se mantenía como el estilo oficial de las grandes academias y salones de Europa y América. Por otro lado, la mirada del hombre representado apunta hacia la esquina superior derecha y el diseño de su postura proyecta una cierta sensualidad, lo cual evidencian una influencia romántica en el estilo del diseñador de este grabado.

Ahora, volviendo a lo que hemos identificado, habíamos señalado a un hombre desnudo el cual calzaba un par de sandalias con alas, un sombrero también alado y sostenía una especie de bastón entre sus manos. ¿Quién es?

Realizando un breve repaso por la historia del arte descubrimos que estos atributos caracterizan al dios griego Hermes ${ }^{13}$; sin embargo, estos atributos también podrían caracterizar a una alegoría a este dios ${ }^{14}$. Por ello debemos de consultar las fuentes clásicas donde se describe a Hermes, para constatar así que este es el personaje que vemos en nuestro billete, o bien una caracterización del mismo. En este caso nos remitiremos a imágenes, de la misma manera que a texto; iniciando con bases escritas, utilizaremos a uno de los autores griegos que más textos legaron a la sociedad occidental, heredándonos sus mitos e historias fantásticas, las cuales fuesen redactadas a través de himnos, poemas y demás relatos de carácter mitológico: por supuesto nos referimos a Homero.

${ }^{12}$ En relación al diseño de este billete, podemos compararlo con ejemplares contemporáneos (Fig. 4 y 5) de otras regiones americanas y así constatar que se obedecía a un estilo internacional. Inclusive la mayoría de estos billetes no eran diseñados ni impresos en sus países de emisión, sino que eran producidos en el extranjero, siendo los sitios más acostumbrados —al menos en el caso costarricense - Inglaterra y Estados Unidos de Norteamérica. Como ejemplo de este fenómeno, el ejemplar que analizamos, el cual fuese realizado por la compañía norteamericana American Bank Note Company, firma neoyorquina, la cual llegase a imprimir billetes para 115 países alrededor del mundo, entre ellos Costa Rica.

${ }^{13}$ Mercurio para los romanos.

${ }^{14}$ Podría ser cualquier hombre o mujer con los atributos de Hermes, ya sea un sacerdote clásico o algún rey. 
Será en el himno homérico a Hermes en donde este autor mediterráneo describió la génesis de dicho dios clásico. Es en este texto donde Homero relata el momento en que Hermes decide fabricar sus sandalias, las cuales necesitase para robar el ganado de Apolo ágil y sigilosamente ${ }^{15}$. Además en la Odisea, texto también de Homero, se describe la velocidad y capacidad de volar que posee el calzado especial de Hermes: “(...) al punto ató sus pies áureos divinos talares, que le llevaban sobre el mar y sobre la tierra inmensa con la rapidez del viento, y tomó la vara con la cual adormece a los ojos de los hombres que quiere o despierte a los que duermen" ". Sobre tal bastón, podemos encontrar su origen hacia el final del himno homérico a Hermes, esto en el momento que Apolo decide confiar en el joven Hermes y obsequiarle una pequeña lanza de madera.

Gloria habrá para ti y para tu madre entre los inmortales: voy a decírtelo sinceramente: sí, por este dardo de cornejo, yo te conduciré glorioso y feliz a los inmortales, te haré espléndidos presentes y no te engañaré jamás. (...) te haré mensajero de los inmortales y de todos los hombres, caro y honorable a mi corazón; y te daré luego la hermosísima varita de la felicidad y de la riqueza, áurea, de tres hojas, la cual te guardará incólume, siendo poderosa para todos los dioses en virtud de las palabras y acciones buenas que declaro haber aprendido de la voz de Zeus ${ }^{17}$.

Pues bien, tras corroborar que los atributos presentes en nuestro billete corresponden con lo descrito en las fuentes clásicas, hemos de realizar otra comprobación, pero en este caso será determinada por la comparación con representaciones plásticas anteriores de la figura de Hermes o Mercurio. En primer lugar, revisaremos representaciones del dios Hermes que fuesen producidas durante la Grecia clásica ${ }^{18}$. Por ejemplo, podemos ver el caso de una cerámica roja (Fig. 6), en la cual se presenta a Hermes vistiendo una túnica, barbado y con largos cabellos, con el caduceo en su mano izquierda y calzando un tipo de botas aladas; por otro lado, también consultaremos una escultura (Fig. 7) contemporánea de esta cerámica, en la cual la figura de Hermes es representada totalmente desnuda, con un sombrero

15 “Una vez que hubo gavillado una brazada de ramas lozanas, ató firmemente bajo sus pies las ligeras sandalias con la misma hojarasca que el ilustre Argicida había arrancado para encubrir su ruta desde Pieria, como el que se apresura por un largo camino usando sus propios recursos". HOMERO, Obras completas de Homero, trad. de Luis Segala y Estalella, Barcelona, 1927, p. 543.

${ }^{16}$ HOMERO, Obras completas de Homero..., p. 330.

${ }^{17}$ HOMERO, Obras completas de Homero..., pp. 549-550.

${ }^{18}$ Por Grecia Clásica nos referimos al período histórico que se desarrolló durante el siglo V a.C., en el cual tanto la filosofía como el arte alcanzaron un nivel de madurez e identidad tal, que perduró a lo largo de la historia y fuese asumido como la imagen general de Grecia para la posteridad. Sin embargo, este período fue la segunda parte de los tres momentos históricos en los que ha sido dividida la cultura griega para su estudio: Arcaico, Clásico y Helenístico. 
alado y sandalias con los mismos atributos. En el caso medieval, tomaremos como referencia un manuscrito (Fig. 8) de hacia el siglo XV en el cual se representa a Mercurio en el libro Liber introductorios de Miguel Escoto ${ }^{19}$, revisando este ejemplo, vemos como ya la imagen de Mercurio no responde a un estilo naturalista ni busca la misma finalidad que el caso griego, dando como resultado un sincretismo iconográfico y religioso, debido a que el mismo dibujo de Mercurio representa al dios oriental Nabu; además la vestimenta de este caso se nos presenta confusa, debido a que más que un dios clásico o babilónico, podría parecer que este manuscrito representa a un sacerdote cristiano. Finalmente, nos referiremos a dos casos del Rinascimento italiano; en primer lugar, veremos como en un grabado (Fig. 9) del autor conocido como Baccio Baldini, se representa a Mercurio volando sobre una especie de carreta $^{20}$; a nivel estilístico el diseño mantiene cierta herencia gótica, pero recupera los atributos clásicos que caracterizaban al dios Hermes, siendo estos el caduceo, su sombrero y botas aladas. Sin embargo, no será hasta el Cinquecentto $^{21}$ cuando el arte europeo recuperará totalmente las tradiciones representativas originales de la Grecia clásica, como ejemplo de ello podemos ver el fresco (Fig. 10) ubicado en la Capilla Farnesina en Roma, donde en una de las enjutas de la sala principal se representa al dios Mercurio, el cual se presenta totalmente desnudo y portando sus atributos que los caracterizan como dios clásico: su sombrero alado, el bastón regalado por Apolo y las alas en sus pies. Posterior a esto, el arte francés asumiría los valores del estilo renacentista y los utilizaría como las bases de su Academia de Bellas Artes; academia que se convertiría en la norma oficial del arte europeo. Noción de arte, estilo y temáticas que fuesen importadas a América durante el proceso de conquista y colonia.

Hasta ahora nos hemos asegurado de constatar que el personaje que vemos en el billete de 1 colón corresponde a Hermes, y que cumple con la iconografía clásica de este dios grecolatino; pero evidentemente esto no nos bastará para determinar qué simboliza la figura de esta deidad europea en un ejemplar de papel moneda perteneciente a un país centroamericano de inicios del siglo XX. Además, al consultar fuentes clásicas, medievales y modernas, nunca se hace mención de

\footnotetext{
${ }^{19}$ Manuscritos en donde se representan a los dioses clásicos a través de la copia de manuscritos árabes y reproduciéndolos siguiendo patrones nuevamente europeos.

${ }^{20}$ Los dioses clásicos sobrevivieron a la Edad Media refugiados en las estrellas, esto porque perdieron su carácter de divinidades, siendo asumidos como planetas y demás cuerpos celestes del universo. Manteniendo sus nombres y atributos, pero cumpliendo un rol distinto, ahora relacionado con la creencia en un determinismo astrológico. Parte de esta herencia medieval se vio reflejada en la temática de los planetas y sus hijos, en la cual se representaba a cada astro encima de las personas que nacieran bajo la influencia de dicho cuerpo celeste.

${ }^{21}$ Siglo XVI.
} 
algún Hermes o Mercurio que esté sentado sobre una imprenta; esto por razones obvias, debido a que esta clase de imprenta corresponde a la maquinaria utilizada durante la segunda mitad del siglo XIX ${ }^{22}$.

¿Por qué se utilizó la efigie de Hermes sentado sobre una imprenta en el billete de 1 colón del Banco Anglo Costarricense emitido entre los años de 1903 a 1917 ?

Para responder a esta pregunta dejaremos por un momento al arte a un lado y nos enfocaremos en el estudio de un ámbito en el que hasta ahora no habíamos ahondado: la filosofía.

Como mencionamos al inicio del presente ensayo, la Costa Rica de inicios de siglo XX era heredera inmediata del proceso liberal iniciado en la segunda mitad del siglo XIX, aproximadamente hacia el año de $1870^{23}$ con la llegada de los liberales al poder. Fue con esta nueva oleada ideológica con la que se empezara una transformación de la cultura costarricense, así como se sentaran las bases de un proyecto identitario que se desarrolló a lo largo del siglo XX hasta dar como resultado la Costa Rica actual. Pero regresando a 1903, la ideología liberal imperaba entre los intelectuales costarricenses, quienes eran acérrimos lectores de textos de la Ilustración, filosofía clásica, y más importante aún, Positivismo social. Y es que la influencia que tuvo el Positivismo social para muchos pueblos americanos radicó en la visión de una cultura mundial — promulgada por esta filosofía-, en la cual la sociedad era vista de manera jerárquica a nivel cultural, o sea, "según esta ideología y por medio de un proceso gradual de cambio, la sociedad iba a transitar por la senda del progreso para pasar de la 'barbarie' a la 'civilización', pero para lograrlo era necesario la consolidación de un estado fuerte que controlara la anarquía social" 24 .

\footnotetext{
${ }^{22}$ Por ejemplo podemos comparar la imprenta grabada en el billete, con un ejemplar de una máquina de imprimir (Fig. 11) fabricada por la marca alemana Köenig \& Bauer durante el siglo XIX.

${ }^{23}$ Tras la renuncia del entonces presidente Bruno Carranza Ramírez, la Asamblea Constituyente nombró al General Tomás Guardia Gutiérrez como el nuevo presidente de Costa Rica. Con la llegada de este militar a la presidencia, se inició una nueva generación de políticos liberales que se mantendrían en el poder hasta la década de 1930. Sintomático del pensamiento liberal de Guardia, hacia 1871 se aprobó la Constitución liberal de 1871, en la cual se independizó a los tres poderes de la Republica, se legalizó la libertad de culto, se abolió la pena de muerte y se aumentó la inversión en la educación del país. Todas estas medidas siguiendo los ideales liberales de secularización del Estado, educación, salubridad, orden y progreso.

${ }^{24}$ F. QUESADA AVENDAÑO, La modernización entre cafetales..., p. 75.
} 
Esta filosofía contó con diversos autores, pero en el caso específico de Centroamérica ${ }^{25}$, varios investigadores como el sociólogo estadounidense James Mahoney, señalan como la mayor influencia intelectual al pensador francés $\mathrm{Au}-$ guste Comte $^{26}$.

En América Latina, para los espíritus liberales, Comte representó la secularización de la historia al cancelar el carácter providencialista de ésta y afirmar su reemplazo por una historia científica que marchaba al ritmo del progreso. (...) Fue con ese horizonte que se formularon los proyectos de sociedad en la segunda mitad del siglo XIX en América Latina. Se trataba de un proyecto que insistía en occidentalizar e incorporar las nuevas ideas europeas de la razón y el liberalismo, más que en definir una identidad nacional ${ }^{27}$.

Siguiendo esta perspectiva filosófica, el Positivismo plantea un ascenso social que finalmente logrará una universalización del conocimiento, la ciencia, el arte, y por ende la cultura ${ }^{28}$. Comte atacaba las nociones nacionalistas y defendía la idea de una sociedad universal regida por el espíritu positivo, sin embargo, esta cultura universal $^{29}$ tomaría como base la cultura europea de la época. Esto debido

\footnotetext{
${ }^{25}$ En efecto, Costa Rica también se vio influenciada por la filosofía positivista de Auguste Comte, esto es corroborable al consultar la base de datos del Sistema Nacional de Bibliotecas (SINABI), en el cual se encuentran registros de los textos: Principios de filosofia positiva Auguste Comte ; tr. de Jorge Lagarrigue, fechado en 1875 e impreso por la librería Mercurio de Chile; por otro lado, Cours de philosophie positive extrait a l'usage des candidats aux baccaluréats Auguste Comte ; précédé d'un exposé sommaire de la vie et de l'oeuvre du fondateur du positivisme, fechado en 1899 y proveniente de la librería Charles Delagrave de Paris. La documentación de estos dos libros son solo ejemplo de como la literatura y filosofía contemporánea europeas eran estudiadas por los intelectuales costarricenses de la época.

26 “¿Qué entiende Comte por «Conocimiento positivo»? Se trata de un conocimiento que se basa en la observación de los hechos (fenómenos) y de las leyes que describen su funcionamiento. En otras palabras, Comte parte de una concepción fenomenista del conocimiento humano, que restringe su campo de acción solo a los hechos empíricamente verificados. En consecuencia, las ciencias naturales constituyen el conocimiento, mientras que la teología y la metafísica carecen de base científica, a causa de su vana pretensión de ir más allá del conocimiento empírico". M. FAZIO, Historia de la Filosofía IV. Filosofia Contemporánea, Madrid, 2004, p. 174.

${ }^{27}$ H. NAHUELPÁN MORENO, "El sueño de la identidad latinoamericana o la búsqueda de lo propio en lo ajeno", Revista Atenea, Chile (2007), p. 161.

28 “Considerado luego especialmente en cuanto al Orden, el espíritu positivo le ofrece hoy, en su extensión social, poderosas garantías directas, no sólo científicas, sino también lógicas, que podrán juzgarse pronto como muy superiores a las pretensiones vanas de una teología retrógrada, cada vez más degenerada, desde hace varios siglos, en activo elemento de discordias, individuales o nacionales, e incapaz en delante de contener las divagaciones subversivas de sus propios adeptos. Atacando al desorden actual en su verdadero origen, necesariamente mental, constituye, tan profundamente como es posible, la armonía lógica, regenerando primero los métodos antes que las doctrinas, por una triple conversión simultánea de la naturaleza de las cuestiones dominantes, de la manera de tratarlas y de las condiciones previas de su elaboración”. A. COMTE, Discurso sobre el espiritu positivo, 1844, p. 27.

29 “Tal es el principio espontáneo de la íntima conexión que, sentida tarde o temprano, unirá necesariamente al instinto popular con la acción social de la filosofía positiva, pues esta gran trans-
} 
a que como señalamos antes — para la mentalidad latinoamericana la cual aún era de colonia - se consideraba que el sub-continente americano vivía una disputa entre la barbarie y la civilización. "La primera venía a representar a Europa y Estados Unidos; mientras que la segunda estaba ligada al mundo indígena y a la inferioridad racial. Dicha dicotomía fue expresada en la oposición entre ciudad y campo" 30 . Y para lograr esto, una sociedad que decidiera asumir el espíritu positivo tendría que "organizar una llamada directa y sostenida al buen sentido universal, esforzándose desde ahora en propagar sistemáticamente, en la masa activa, los principales estudios científicos propios para constituir en ella la base indispensable de su gran elaboración filosófica" ${ }^{31}$.

Ahora bien, para lograr este objetivo de unificación del pensamiento y cultura, los gobiernos positivos tendrían que preocuparse no solo por moralizar a la élite, sino también al pueblo:

Este magno resultado no podría obtenerse de un modo suficiente si esta enseñanza continua permaneciera destinada a una sola clase cualquiera, incluso muy extensa; se debe, so pena de fracasar, tener siempre a la vista la universalidad entera de las inteligencias. En el estado normal que este movimiento debe preparar, todas, sin ninguna excepción ni distinción, sentirán siempre la misma necesidad fundamental de esta filosofía primera, que resulta del conjunto de las nociones reales, y que debe entonces llegar a ser la base sistemática de la sabiduría humana, tanto activa como especulativa, de manera que cumpla más convenientemente el indispensable oficio social que se vinculaba en otro tiempo a la instrucción universal cristiana. Importa, pues, mucho que, desde su origen, la nueva escuela filosófica desarrolle, en lo posible, ese gran carácter elemental de universalidad social, que, relativo finalmente a su destino principal, constituirá hoy su mayor fuerza contra las diversas resistencias que ha de encontrar ${ }^{32}$.

De este modo, los Estados positivos debían de servirse de las artes ${ }^{33}$ y en general de las imágenes ${ }^{34}$ para moralizar a la masa de la población. Refiriéndose

formación equivale evidentemente a aquella otra, fundada antes por las más altas consideraciones especulativas, del movimiento político actual en un simple movimiento filosófico, cuyo primero y principal resultado social consistirá, en efecto, en constituir sólidamente una activa moral universal, prescribiendo a cada agente, individual o colectivo, las reglas de conductas más conformes con la armonía fundamental". A. COMTE, Discurso sobre el espíritu positivo, 1844, p. 43.

${ }^{30}$ H. NAHUELPÁN MORENO, "El sueño de la identidad latinoamericana o la búsqueda de lo propio en lo ajeno...", p. 161.

${ }^{31}$ A. COMTE, Discurso sobre el espíritu positivo, 1844, p. 38.

${ }^{32}$ A. COMTE, Discurso sobre el espíritu positivo, 1844, p. 39.

33 "Pues el arte no será ya entonces tan sólo geométrico, mecánico o químico, sino también y sobre todo político y moral, ya que la principal acción ejercida por la Humanidad debe consistir, en todos aspectos, en el mejoramiento continuo de su propia naturaleza, individual o colectiva, entre los límites que indica, como en todos los demás casos, el conjunto de las leyes reales". A. COMTE, Discurso sobre el espíritu positivo, 1844, p. 15. 
Comte así, a una armonía entre ciencia y arte, la cual buscaría desarrollar y consolidar la tan ansiada ascensión social, la cual iba de la mano con la vida industrial de la segunda mitad del siglo XIX ${ }^{35}$.

Costa Rica fue participante activa de este afán por ascender socialmente mediante la canalización del espíritu positivo. De este modo, el proyecto liberal gestó una serie de reformas y cambios —orquestados por los jerarcas políticos y oligarcas en su mayoría-, para así modificar el orden social y en consecuencia, la cultura del país. Ejemplo de esto fue la construcción de numerosos parques y zonas de disfrute público, las cuales fuesen diseñadas siguiendo estándares europeos; por otro lado, la educación sufrió modificaciones a nivel coyuntural, por ejemplo la Universidad de Santo Tomas varió su estatuto en el tránsito de la segunda mitad del siglo XIX, incluyendo entre sus planes de estudios más textos filosóficos de Grecia, Roma, Modernidad e Ilustración, perfilando así la educación hacia un modelo más universal (europeo). Por otro lado, hacia el año de 1897 se funda oficialmente la Escuela Nacional de Bellas Artes, bajo la dirección del pintor español Tomás de Povedano y $\operatorname{Arcos}^{36}$, el cual instauró el academicismo europeo tradicional como la base de la enseñanza en dicha escuela de artes. Finalmente, como máximo ejemplo, destaca la construcción del Teatro Nacional (Fig. 12), inaugurado el 21 de octubre de ese mismo año, iniciando con el Himno Nacional, seguido de La Marsellesa y como obra estelar, la ópera Fausto del compositor francés Charles François Gounod, basada en el libro homónimo del autor alemán Goethe e interpretada por un grupo de artistas franceses. Además de las presentaciones con intención europeizante que se realizaban en el Teatro Nacional, aunado al diseño arquitectónico de dicho inmueble, el cual se nos presenta como una suerte de monumento a Europa. Por ejemplo, el diseño del Teatro Na-

34 "Hasta en las artes más sencillas y perfectas sigue siendo indispensable un constante desarrollo, directo y espontáneo, sin que las indicaciones científicas puedan, en ningún caso, suplirlo completamente". A. COMTE, Discurso sobre el espiritu positivo, 1844, p. 15

35 "Haciendo prevalecer cada vez más la vida industrial, la sociabilidad moderna debe, pues, secundar poderosamente la gran revolución mental que hoy eleva nuestra inteligencia, definitivamente, del régimen teológico al régimen positivo". A. COMTE, Discurso sobre el espíritu positivo, 1844, p. 16.

36 Tomás Povedano (1856-1943), pintor español radicado en Quito, fue el encargado de dirigir la Escuela Nacional de Bellas Artes por indicación del entonces presidente Rafael Yglesias Castro. Ya en 1892 el pintor costarricense Enrique Echandi había propuesto la fundación y futura dirección de una escuela nacional de bellas artes, pero sus desfavorables (políticamente) vínculos familiares y su nacionalidad provocaron el rechazo de su propuesta por parte del entonces presidente José Joaquín Rodríguez. Este acontecimiento retrata la actitud del positivismo social que se reflejó en el menosprecio hacia los artistas costarricenses y la idealización de la supuesta superioridad intelectual europea. 
cional de Costa Rica (Fig. 13) se aproxima al del Teatro de Ópera de París (Fig. 14).

Bajo esta perspectiva, es claro como la Costa Rica de la época buscaba proyectar al máximo su alto nivel cultural. Por otro lado, en consecuencia de la gran importancia que había asumido el comercio internacional del café, Costa Rica había ingresado al mercado internacional ${ }^{37}$, y sin lugar a dudas esta era una oportunidad para demostrar su ascenso cultural, por ello, el papel moneda asumía un rol fundamental, no solo para la moralización de la población, sino también como un medio de proyección internacional. Por ello, -como mencionamos antes- los billetes de la mayor parte de países latinoamericanos seguían un modelo similar a nivel de diseño, esto porque muchas de estas naciones también eran gobernadas económica y políticamente por intelectuales liberales y seguidores del Positivismo social; comprando cada banco los diseños de su papel moneda a compañías estadounidenses, las cuales les ofrecían la esencia del arte europeo ${ }^{38}$. De esta manera, Costa Rica buscó posicionarse como una nación desarrollada y conocedora de la cultura universal, ejemplo de ello, las imágenes de la mitología clásica y las alegorías a los diversos símbolos del Orden y el Progreso.

Tras esta contextualización de la ideología que dominaba en la élite costarricense de la época, podemos preguntarnos nuevamente: ¿Por qué se utilizó la efigie de Hermes sentado sobre una imprenta en el billete de 1 colón del Banco Anglo Costarricense emitido entre los años de 1903 a 1917 ?

Ubicándonos en una sociedad que abogaba por la búsqueda del Orden y Progreso; este ascenso social se vería marcado por distintos valores, ciencias, dis-

37 "La década de 1890 inició con una economía en rápido crecimiento, motivado por dos elementos: primero un fuerte aumento del precio del café entre 1888 y 1896, que llegó a duplicarse respecto a nivel al que había llegado después de una importante caída entre 1880 y 1887; y segundo, por el rápido crecimiento de la exportación bananera, que de ser casi inexistente en 1880, alcanzó la exportación de más de un millón de racimos en 1890 y se triplicó hasta tres millones en 1899. Ambos factores dieron dinamismo a la economía en los primeros 7 años de la década, en la cual a la expansión del consumo privado en esta época, se sumó la del Estado, que una vez concluido el ferrocarril al Atlántico en 1890, dirigió su interés hacia la inversión en edificios públicos (Teatro Nacional, Asilo Chapui) y de educación, así como a otras obras públicas". J. LEÓN, Las políticas económicas en Costa Rica 1890-1950: La primera mitad del siglo XX, s. f., p. 3.

${ }^{38}$ Podemos mencionar al pintor, dibujante y grabador estadounidense Asher Brown Durand (1776-1886) perteneciente a la Escuela del río Hudson, quien trabajó junto a su hermano para la American Bank Note Company desde la primera mitad del siglo XIX. Específicamente se le adjudica a Durand la iniciativa por incluir diseños alegóricos de temática clásica en los prototipos de los billetes del American Bank Note Company (Fig. 15). Sobre el estilo de este artista, es evidente su formación académica, pero también resalta una alta influencia romántica en su obra (Fig. 16). Diferenciando su producción entre pinturas cargadas de color y con una actitud preponderantemente romántica (Fig. 17); por otro lado, sus grabados comerciales se mantuvieron apegados a un marcado academicismo neoclasicista (Fig. 18). 
ciplinas y atributos que — según esta ideología - caracterizaban a las culturas civilizadas. Dando esto como resultado una serie de valores e ideas que fueron materializadas mediante imágenes, las cuales fueron representadas figurativamente mediante alegorías. Alegorías que se remontan a una tradición artística antiquísima que data del arte griego, por ello, el academicismo del siglo XIX había utilizado esta herencia clásico-renacentista, para hacer tangibles diversos valores bases de la ideología liberal, tales como: progreso (Fig. 19), industria, comercio (Fig. 20), agricultura (Fig. 21), seguridad (Fig. 22), ciencia (Fig. 23), artes (Fig. $24)$, invención, entre otros. Y es que en el caso de nuestro billete a analizar, es cierto que la figura que vemos corresponde a la del dios Hermes, pero en este caso no simboliza a esta deidad como tal, sino que su imagen es una alegoría. ¿Cómo afirmar esto? Para esto, hemos de señalar varios aspectos; en primer lugar, entre los diversos atributos de Hermes se encuentra el don de la invención, el cual se ejemplifica en el himno homérico, cuando el recién nacido decide salir de su casa $y$ al ver una tortuga ${ }^{39}$ inmediatamente piensa en hacer una cítara con ella ${ }^{40}$, además cuando decide fabricarse sus sandalias para no hacer ruido ${ }^{41}$, y así existen numerosos mitos que confirmar la capacidad de este dios para imaginar y producir cosas; en segundo lugar, Hermes se encuentra sentado sobre una de las imprentas más modernas de la época, máquina que representa la Revolución Industrial, la era de la reproductividad técnica, la información y el comercio; y en tercer lugar, se cuentan con ejemplos contemporáneos ${ }^{42}$ donde Hermes es utilizado como alegoría, ya sea para representar al comercio, la invención, la industria u otros valores.

39 “Allí encontró una tortuga y con ella adquirió un inmenso tesoro: Hermes, en efecto, fue quien primeramente hizo que cantara la tortuga, que le salió al encuentro en la puerta exterior, paciendo la verde hierba delante de la morada y andando lentamente con sus pies". HOMERO, Obras completas de Homero..., p. 541.

40 "Como cuando un pensamiento fugaz atraviesa por el ánimo de un varón al que asedian múltiples preocupaciones o como cuando saltan desde los ojos las miradas chispeantes, así pensaba a la vez la palabra y la acción el glorioso Hermes. Una vez que cortó en sus justas medidas tallos de caña, los atravesó, perforando el dorso, a través de la concha de la tortuga. Alrededor tendió una piel de vaca, con la inteligencia que le es propia, le añadió un codo, los ajustó a ambos con un puente y tensó siete cuerdas de tripa de oveja, armonizadas entre sí". HOMERO, Obras completas de Homero..., p. 542.

41 “Tiró en seguida las sandalias sobre la arena del mar y trenzó otras que sería difícil explicar o entender, ¡cosa admirable!, entrelazando ramos de tamarisco con otros que parecían de mirto". HOMERO, Obras completas de Homero..., p. 543.

${ }^{42}$ Destaca el diseño de un billete chino del mismo año que el billete costarricense, en el cual se representa un Hermes sentado junto a una máquina (Fig. 25). Además existen diversos diseños realizados en Estados Unidos entre los siglos XIX y XX en donde se representa a Hermes en diversas alegorías (Fig. 26, 27, 28 y 29). 
Regresando al contexto costarricense, el Teatro Nacional alberga en sus paredes dos ejemplos de cómo las alegorías referentes a Hermes eran comunes en el arte consumido por la élite de la época. Denotando esto con el óleo del pintor italiano Paolo Serra, titulado "El comercio" (Fig. 30), parte de las numerosas pinturas importadas directamente de Europa para decorar las diversas salas del Teatro Nacional, representación en que una mujer portadora de los atributos de Mercurio representa este valor estandarte de la ideología liberal; por otro lado, está el caso de una pintura posterior a la tela de Serra, del antes mencionado Tomás Povedano, quien representó también "El comercio" (Fig. 31), pero que a diferencia del italiano Povedano sí representó al Comercio con la efigie del dios Mercurio como tal.

\section{CONCLUSIONES.}

Finalmente, tras haber analizado iconográfica e iconológicamente el diseño del reverso del billete de 1 colón emitido por el Banco Anglo Costarricense hacia 1903, es evidente como esta imagen representa a la élite costarricense de la época; constituyéndose como un síntoma del fallido proyecto de modernización de Costa Rica, el cual solo fue aplicado a la ciudad de San José y que en consecuencia, aumentó las brechas sociales entre la clase adinerada y resto de la población. Estos valores del espíritu positivo solo fueron asumidos por los intelectuales, debido a que solo reducidos círculos sociales tuvieron acceso a la información, capital económico, poder y medios para - al menos - intentar —o desear - realizar el proyecto liberal; por otro lado, el resto de la población se mantuvo avocada a sus labores cotidianas, perteneciendo a la cultura popular.

Hermes fue representado junto a una imprenta de billetes como alegoría al creciente comercio costarricense que desde la segunda mitad del XIX perfilaba a Costa Rica como un país agrícola que se europeizaba cada día más, todo con el objetivo de ascender en el mercado internacional y reforzar la economía de la nación, o más específicamente, de la oligarquía intelectual y los jerarcas políticos con ideología liberal.

\section{BIBLIOGRAFÍA Y FUENTES DE REFERENCIA.}

J. CARRANZA ASTÚA. Historia de los billetes de Costa Rica 1858-2012: vales, billetes, especímenes, pruebas, errores. San José, 2012. 
M. CHACÓN HIDALGO; I. ALVARADO VENEGAS. Gráfica en el papel moneda (1858-1936). San José, 2001.

M. CHACÓN HIDALGO. El papel moneda: folleto técnico. San José, 1999.

A. COMTE. Discurso sobre el espíritu positivo. 1844. Versión digitalizada por Librodot.com, Recuperado el 19 de febrero del 2013 de: http://espanol.freeebooks.net/tos.html

M. FAZIO. Historia de la Filosofía IV. Filosofía Contemporánea. Madrid, 2004.

L. FERRERO ACOSTA. Sociedad y arte en la Costa Rica del siglo XIX. San José, 1986.

W. GRIFFITHS. The Story of American Bank Note Company, New York, 1959.

HOMERO. Obras completas de Homero. Trad. de Luis Segala y Estalella. Barcelona, 1927.

J. LEÓN. Las políticas económicas en Costa Rica 1890-1950: La primera mitad del siglo XX. San José. Disponible en: http://www.iice.ucr.ac.cr/Politica Economica1890-1950.pdf

I. MOLINA JIMÉNEZ. Costarricense por dicha: identidad nacional y cambio cultural en Costa Rica durante los siglos XIX y XX. San José, 2002.

Moradas y discursos. Cultura política en la Costa Rica de los siglos XIX $y X X$. Heredia, 2010.

I. MOLINA JIMÉNEZ.; S. PALMER. Héroes al gusto y libros de moda: sociedad y cambio cultural en Costa Rica 1750-1900. San José, 1992.

H. NAHUELPÁN MORENO. "El sueño de la identidad latinoamericana o la búsqueda de lo propio en lo ajeno" Revista Atenea. Chile, 2007.

E. PANOFSKY. El significado en las artes visuales. Madrid: Alianza EditoriaL, 1955.

On the Relationship of Art History and Art Theory: Towards the Possibility of a Fundamental System of Concepts for a Science of Art. Trad. Jas' Elsner; Katharina Lorenz. Critical Inquiry. Chicago, 2008.

F. QUESADA AVENDAÑO. La modernización entre cafetales. San José, Costa Rica, 1880-1930. Helsinki, 2007.

A. PICK. Standard Catalog of World Paper Money "Volume One: Specialized Issues". Estados Unidos, 1998.

A. PICK. Standard Catalog of World Paper Money "Volume Two: General Issues: 1368-1960". Estados Unidos, 2000.

THE HUDSON RIVER MUSEUM (1983). Asher B. Durand: An Engraver's and a Farmer's Art. New York, 1983. 
Progreso y CULTURA: ICONOLOGíA DEL PAPEL MONEDA DE COSTA RICA EN EL PERÍODO LIBERAL

WIKIMEDIA COMMONS. Wikipedia. Recurso disponible en línea en: http://commons.wikimedia.org/wiki

WARBURG INSTITUTE ICONOGRAPHIC DATABASE. London. Recurso disponible en línea en: http://warburg.sas.ac.uk/vpc/VPC_search/main_page .php

\section{IMÁGENES.}
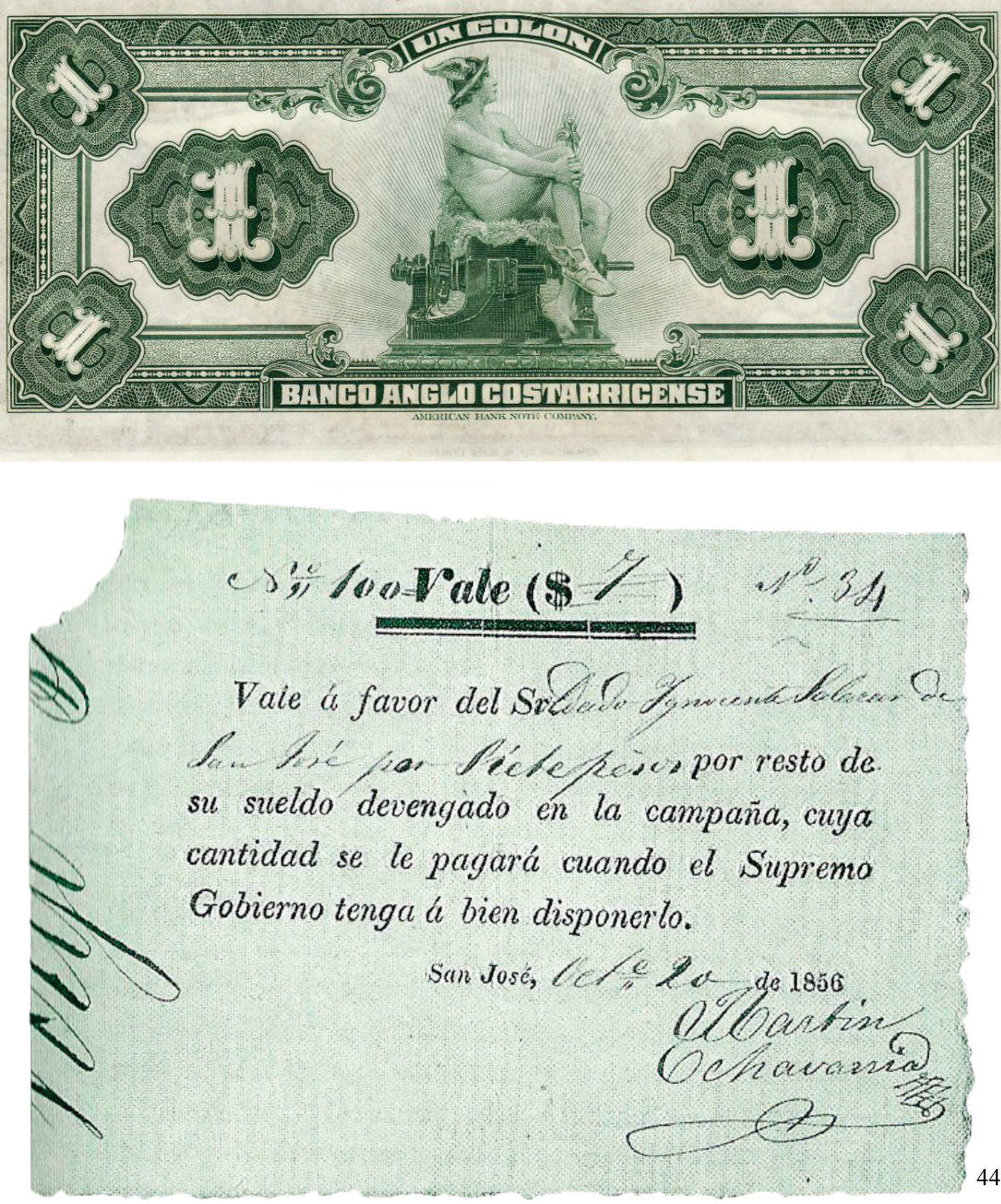

${ }^{43}$ Figura 1. Banco Anglo Costarricense, Reverso: Billete de 1 colón (inédito), 1917 (diseño de 1903), serie A \# 047712, impreso por American Bank Note Company, 15,2 x 6,8 cm.

${ }^{44}$ Figura 2. Gobierno de la República de Costa Rica, Vale por 7 pesos, 1856, Emitidos durante la Campaña Nacional contra la invasión norteamericana de 1856. 

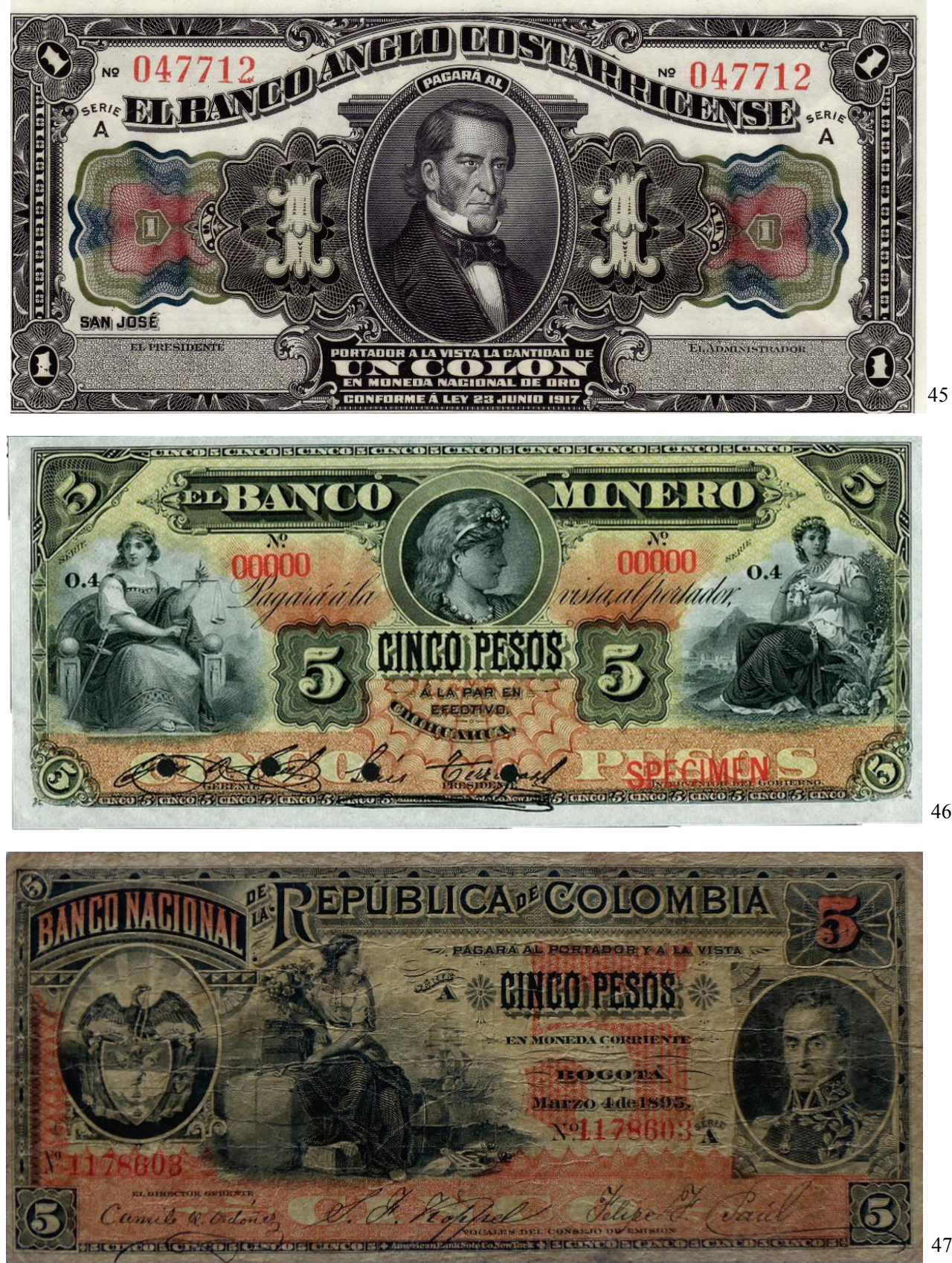

${ }^{45}$ Figura 3. Banco Anglo Costarricense, Anverso: Billete de 1 colón (inédito), 1917 (diseño de 1903), serie A \# 047712, impreso por American Bank Note Company, 15,2 x 6,8 cm.

${ }^{46}$ Figura 4. Banco Minero de Chihuahua, Anverso: Billete de 5 pesos (espécimen), 18881914, impreso por American Bank Note Company

${ }^{47}$ Figura 5. Banco Nacional de la República de Colombia, Anverso: Billete de 5 pesos, 1895, Serie A \#1178608, impreso por American Bank Note Company. 
LEONARDO SANTAMARÍA MONTERO

Progreso y Cultura: ICONOLOGÍA DEL PAPEL MONEDA DE COSTA RicA EN EL PERÍODO LIBERAL
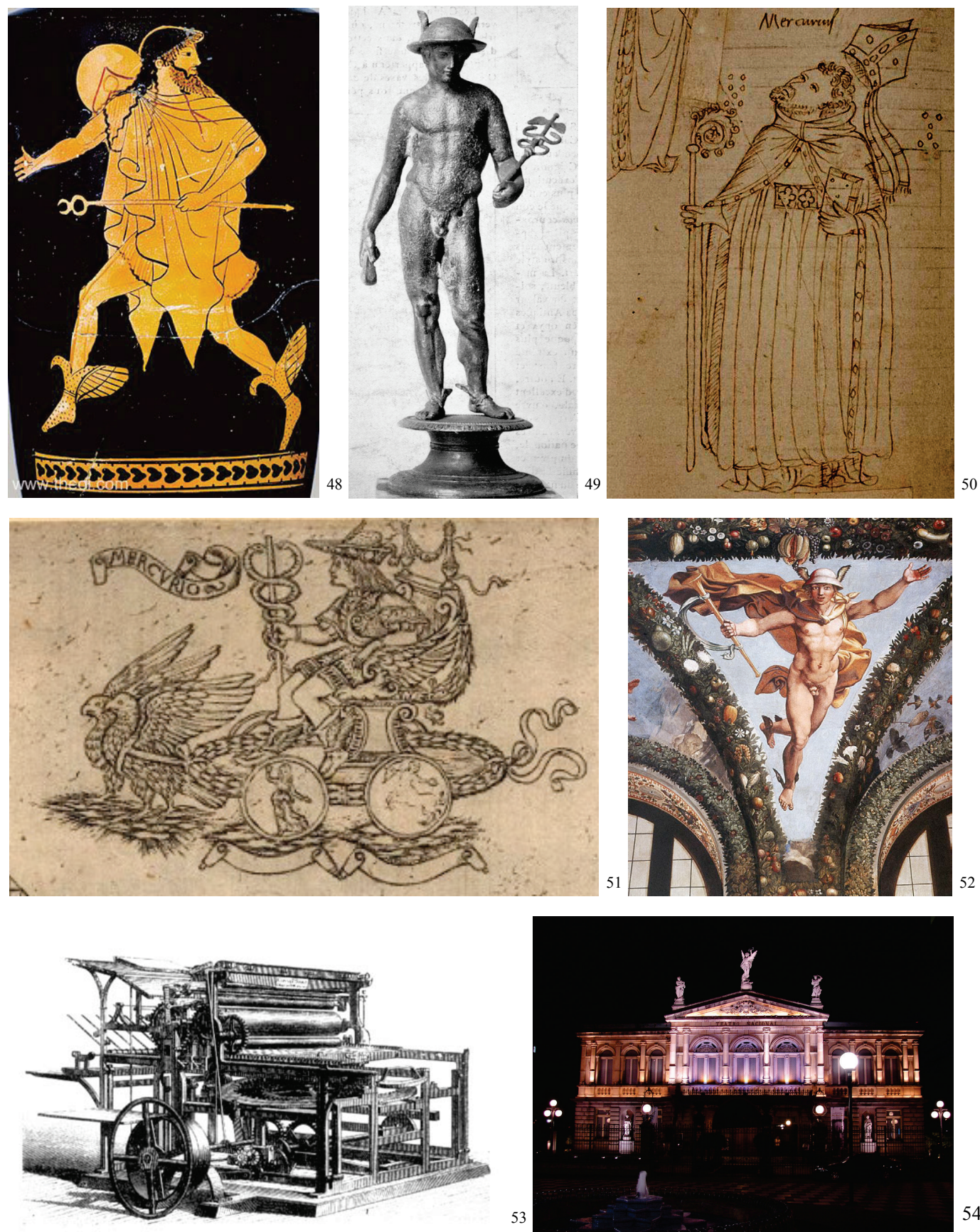

${ }^{48}$ Figura 6. Autor desconocido, Hermes, cerámica roja, siglo V a.C.

${ }^{49}$ Figura 7. Autor desconocido, Hermes, bronce, siglo IV a.C.

50 Figura 8. Migue Escoto, Mercurio "Liber Introductorius", dibujo, siglo XV, MS Bodl. 266F115 R

${ }^{51}$ Figura 9. Detalle. Hijos del planeta mercurio, perteneciente al calendario del llamado Baccio Baldini, grabado, h.1460.

52 Figura 10. Julio Romano, Francesco Penni, y Geovanni da Udini, Mercurio, Enjuta, fresco, 1518-1520. Villa Farnesina (Roma). 
LEONARDO SANTAMARÍA MONTERO

Progreso y Cultura: ICONOLOGÍA DEL PAPEL MONEDA DE COSTA RICA EN EL PERÍODO LIBERAL
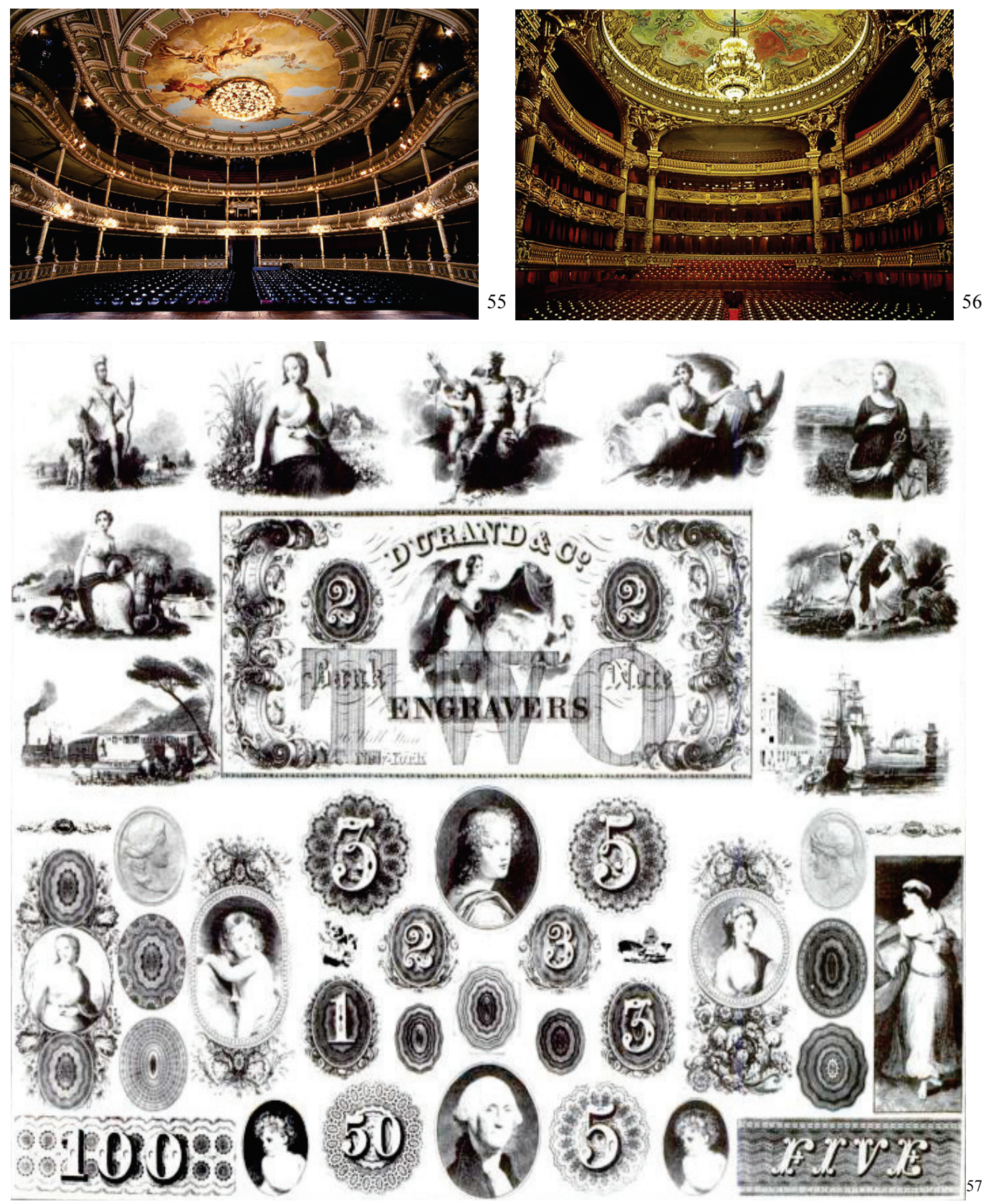

${ }^{53}$ Figura 11. Autor desconocido, Máquina de imprimir, Köenig \& Bauer, tipográfica, con movimiento hipocicliodal, grabado en metal, siglo XIX.

${ }^{54}$ Figura 12. Teatro Nacional de Costa Rica, 1890-1897, San José.

${ }^{55}$ Figura 13. Proscenio del Teatro Nacional de Costa Rica.

${ }^{56}$ Figura 14. Charles Garnier, Proscenio del Ópera de París, madera, piedra, hierro, oro y mármol, 1861-1875, París.

${ }^{57}$ Figura 15. Asher B. Durand. Specimen sheet, grabado en metal, 1839-1842. 
LEONARDO SANTAMARÍA MONTERO

Progreso y Cultura: ICONOLOGÍA DEL PAPEL MONEDA DE COSTA RiCA EN EL PERÍODO LIBERAL
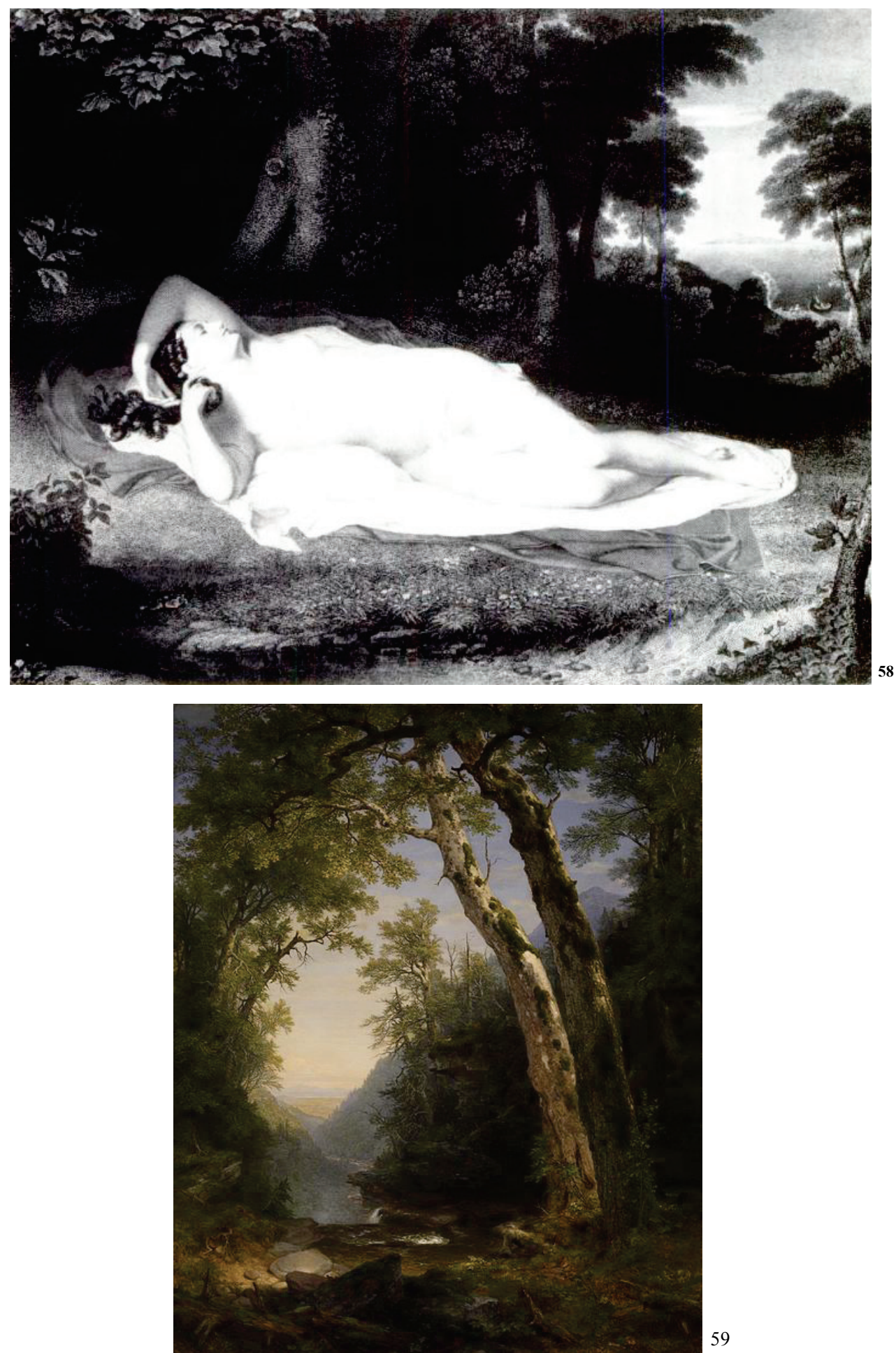

${ }^{58}$ Figura 16. Asher B. Durand. Ariadne. Copia de la pintura de J. Vanderlyn, grabado en metal, 1835.

${ }^{59}$ Figura 17. Asher B. Durand, The Catskills, óleo sobre lienzo, 1859. 
LEONARDO SANTAMARÍA MONTERO

PROGReso y CUltura: ICONOLOGÍA DEL PAPEL MONEDA DE COSTA RiCA EN EL PERÍODO LIBERAL
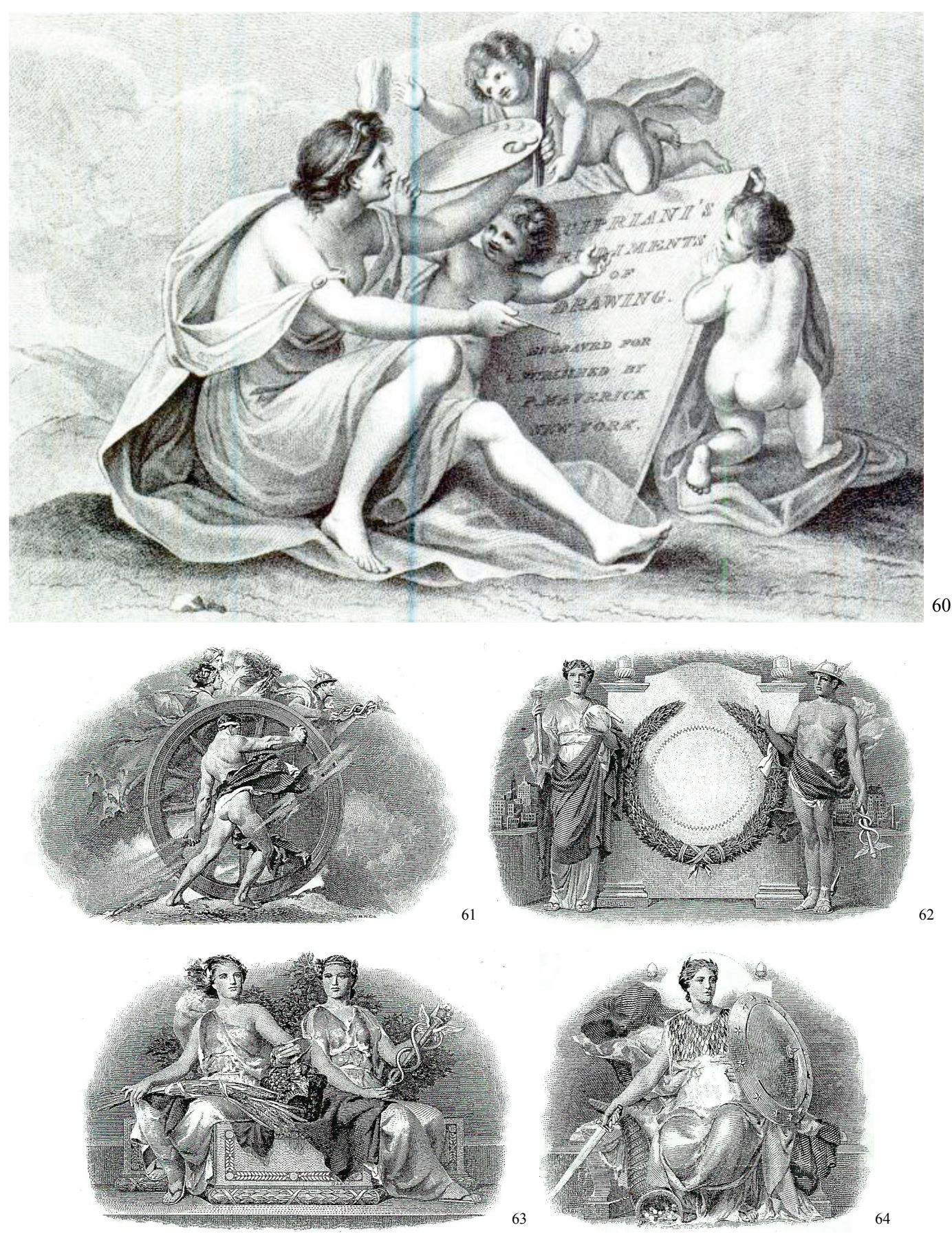

${ }^{60}$ Figura 18. Asher B. Durand, Portada para el libro de dibujo de Giovanni Battista Cipriani "Rudiments of Drawing", grabado en metal, 1818.

${ }^{61}$ Figura 19. Autor desconocido (ABNC), Alegoría al progreso, grabado en metal, s.f.

${ }^{62}$ Figura 20. Autor desconocido (ABNC), Alegoría al comercio, grabado en metal, s.f.

${ }^{63}$ Figura 21. Autor desconocido (ABNC), Alegoría a la agricultura, grabado en metal, s.f.

${ }^{64}$ Figura 22. Autor desconocido (ABNC), Alegoría a la seguridad, grabado en metal, s.f. 
LEONARDO SANTAMARÍA MONTERO

PROGReSO Y CULTURA: ICONOLOGÍA DEL PAPEL MONEDA DE COSTA RiCA EN EL PERÍODO LIBERAL
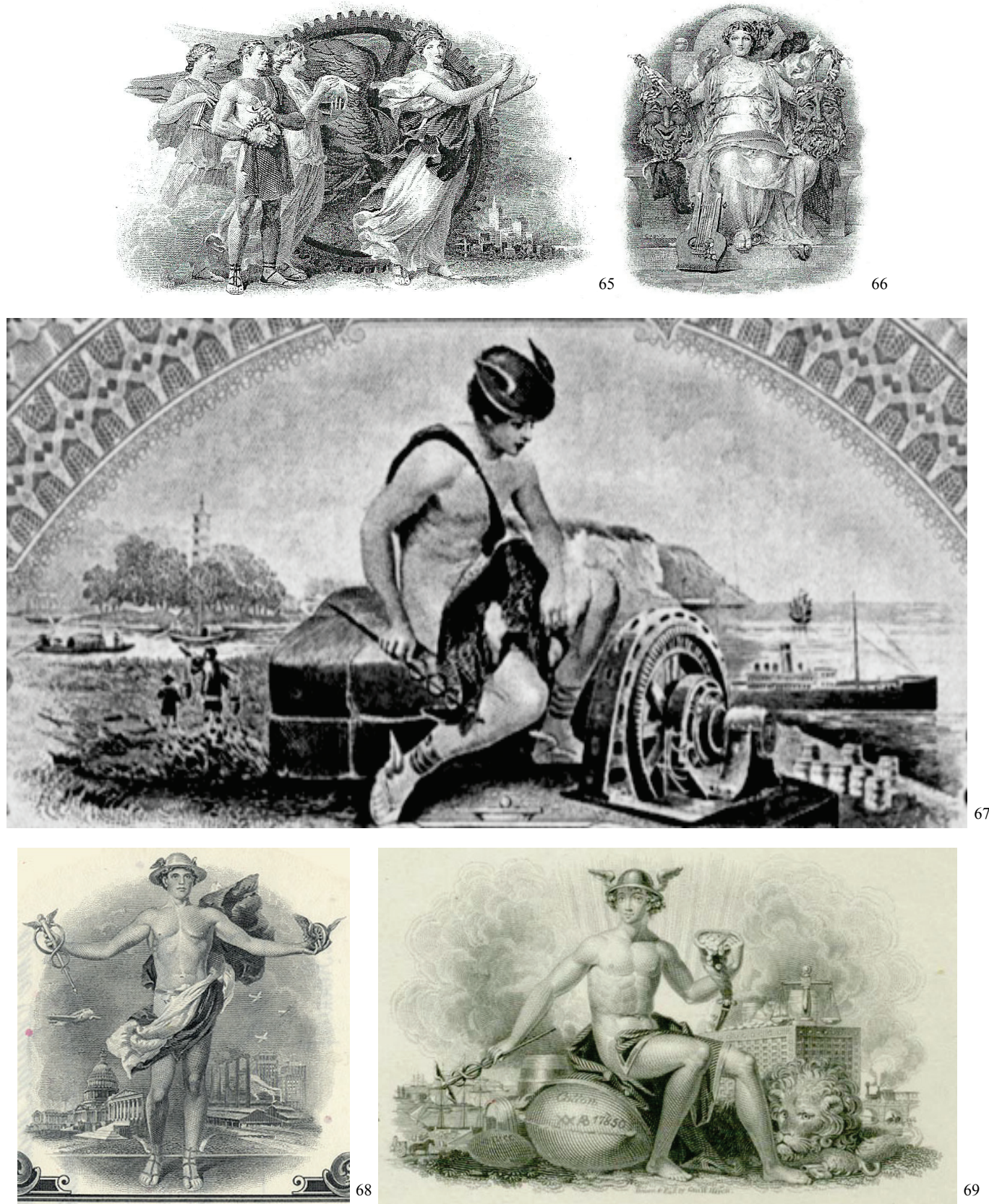

${ }^{65}$ Figura 23. Autor desconocido (ABNC), Alegoría a la ciencia, grabado en metal, s.f.

${ }^{66}$ Figura 24. Autor desconocido (ABNC), Alegoría a la música y el drama, grabado en metal, s.f.

${ }^{67}$ Figura 25. Detalle. Billete del gobierno chino, 1903.

${ }^{68}$ Figura 26. Autor estadounidense desconocido, Alegoría al progreso, grabado en metal, s.f.

${ }^{69}$ Figura 27. Autor estadounidense desconocido, Alegoría a la industria, grabado en metal, s.f. 
LEONARDO SANTAMARÍA MONTERO

Progreso y Cultura: ICONOLOGÍA DEL PAPEL MONEDA DE COSTA RiCA EN El PERÍODO LIBERAL
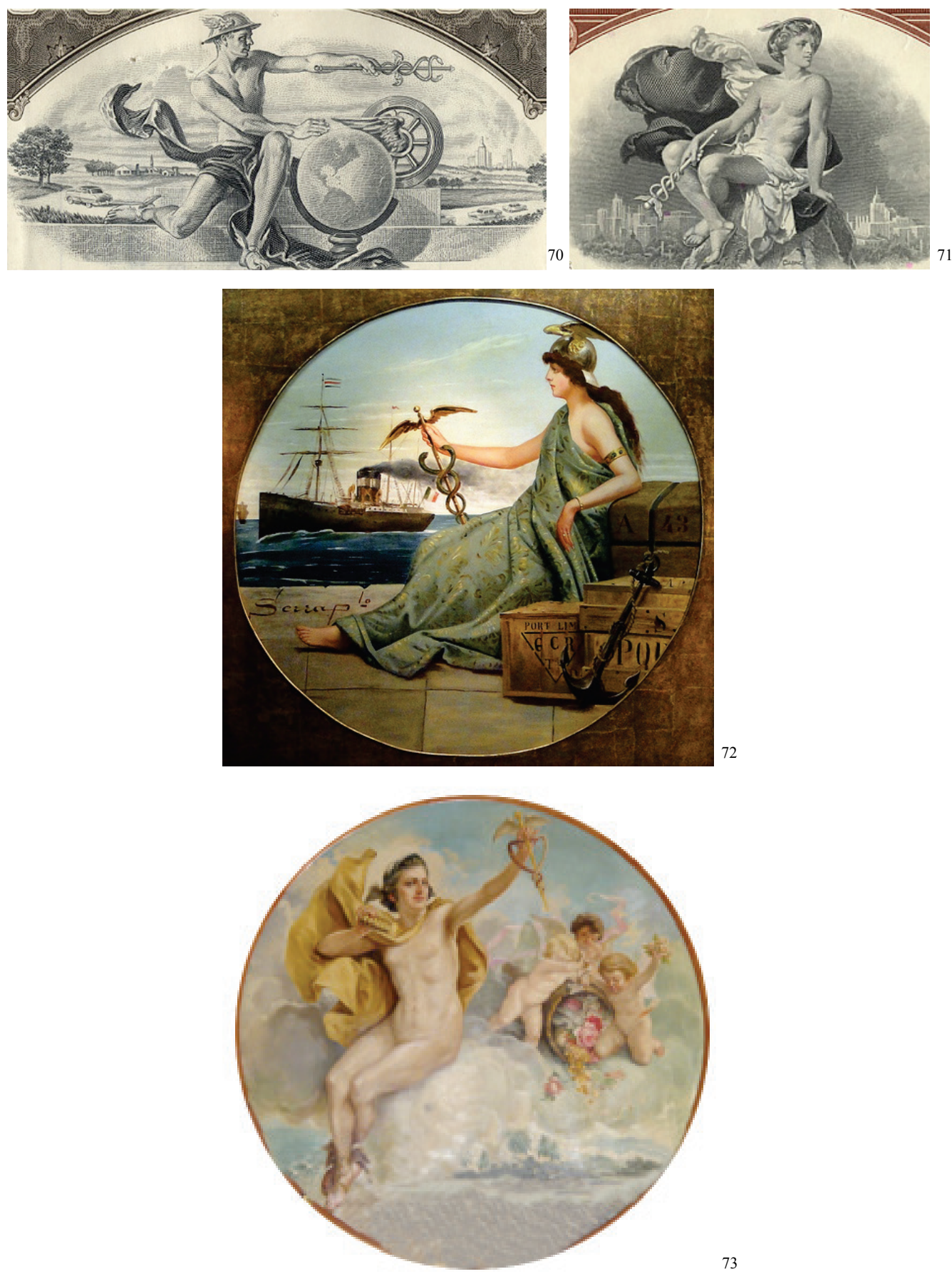

73

${ }^{70}$ Figura 28. Autor estadounidense desconocido, Alegoría al comercio, grabado en metal, s.f. ${ }^{71}$ Figura 29. Autor estadounidense desconocido, Alegoría al progreso, grabado en metal, s.f.

${ }^{72}$ Figura 30. Paolo Serra, El comercio, óleo sobre lienzo, 1897, Teatro Nacional de Costa Rica. Costa Rica.

${ }^{73}$ Figura 31. Tomás Povedano, El comercio, óleo sobre lienzo, 1912, Teatro Nacional de 